\title{
Retrograde Suppression of Post-Tetanic Potentiation at the Mossy Fiber-CA3 Pyramidal Cell Synapse
}

\author{
Sachin Makani,, ${ }^{1, *}$ Stefano Lutzu, ${ }^{1, *}$ Pablo J. Lituma, ${ }^{1, *}$ David L. Hunt, ${ }^{1}$ and Pablo E. Castillo ${ }^{1,2}$ \\ https://doi.org/10.1523/ENEURO.0450-20.2021 \\ ${ }^{1}$ Dominick P. Purpura Department of Neuroscience, Albert Einstein College of Medicine, Bronx, NY 10461 and \\ ${ }^{2}$ Department of Psychiatry and Behavioral Sciences, Albert Einstein College of Medicine, Bronx, NY 10461
}

\begin{abstract}
In the hippocampus, the excitatory synapse between dentate granule cell (GC) axons, or mossy fibers (MFs), and CA3 pyramidal cells (MF-CA3) expresses robust forms of short-term plasticity, such as frequency facilitation and post-tetanic potentiation (PTP). These forms of plasticity are due to increases in presynaptic neurotransmitter release, and can be engaged when dentate GCs fire in bursts (e.g., during exploratory behaviors) and bring CA3 pyramidal neurons above threshold. While frequency facilitation at this synapse is limited by endogenous activation of presynaptic metabotropic glutamate receptors (mGluRs), whether MF-PTP can be regulated in an activity-dependent manner is unknown. Here, using physiologically relevant patterns of MF stimulation in acute mouse hippocampal slices, we found that disrupting postsynaptic $\mathrm{Ca}^{2+}$ dynamics increases MF-PTP, strongly suggesting a form of $\mathrm{Ca}^{2+}$-dependent retrograde suppression of this form of plasticity. PTP suppression requires a few seconds of MF bursting activity and $\mathrm{Ca}^{2+}$ release from internal stores. Our findings raise the possibility that the powerful MF-CA3 synapse can negatively regulate its own strength not only during PTP-inducing activity typical of normal exploratory behaviors, but also during epileptic activity.
\end{abstract}

Key words: calcium; hippocampus; mossy fiber; presynaptic; retrograde signaling; short-term plasticity

\section{Significance Statement}

The powerful mossy fiber (MF)-CA3 synapse exhibits strong forms of plasticity that are engaged during location-specific exploration, when dentate granule cells (GCs) fire in bursts. While this synapse is wellknown for its presynaptically expressed long-term potentiation (LTP) and long-term depression (LTD), much less is known about the robust changes that occur on a shorter time scale. How such short-term plasticity is regulated, in particular, remains poorly understood. Unexpectedly, a GC in vivo like pattern of activity induced robust presynaptically-expressed post-tetanic potentiation (PTP) only when the postsynaptic cell was loaded with a high concentration of $\mathrm{Ca}^{2+}$ buffer, indicating a form of $\mathrm{Ca}^{2+}$-dependent retrograde suppression of PTP. Such suppression may have profound implications for how environmental cues are encoded into neural assemblies, and for limiting network hyperexcitability during seizures.

\section{Introduction}

Mossy fibers (MFs), the axonal projections of dentate granule cells (GCs), provide a strong excitatory input onto hippocampal CA3 pyramidal neurons (Henze et al., 2000; Nicoll and Schmitz, 2005). The MF-CA3 synapse is well

Received October 19, 2020; accepted January 16, 2021; First published February 16, 2021.

The authors declare no competing financial interests. known for exhibiting uniquely strong forms of short-term potentiation, including paired-pulse facilitation (PPF) and frequency facilitation, which last milliseconds to seconds (Salin et al., 1996). More intense periods of high-frequency stimulation typically elicit post-tetanic potentiation (PTP; e.g., MF-

Author contributions: S.M., S.L., P.J.L., D.L.H., and P.E.C. designed research; S.M., S.L., and P.J.L. performed research; S.M., S.L., and P.J.L. analyzed data; S.M., S.L., P.J.L., and P.E.C. wrote the paper. 
PTP), which decays over several minutes (Griffith, 1990). These forms of plasticity are commonly attributed to an increase in presynaptic release probability (Pr; Zucker and Regehr, 2002; Nicoll and Schmitz, 2005; Regehr, 2012), a change in the readily releasable pool (Vandael et al., 2020), and transiently convert the synapse from a high-pass to lower-pass filter (Abbott and Regehr, 2004). In behaving rodents, during place field activation, GCs can fire in high-frequency bursts (PerníaAndrade and Jonas, 2014; Diamantaki et al., 2016; GoodSmith et al., 2017; Senzai and Buzsáki, 2017), driving CA3 pyramidal neurons above threshold (Henze et al., 2002). Thus, frequency facilitation and MF-PTP could have a profound impact on how memory traces are encoded into CA3 neural ensembles.

Given the apparent ease with which these robust forms of presynaptic potentiation are elicited at the MF-CA3 synapse, one might expect a process by which the connection is negatively regulated. In fact, there is evidence that endogenously released glutamate transiently suppresses frequency facilitation via presynaptic Group II metabotropic glutamate receptors (II-mGluRs; Scanziani et al., 1997; Toth et al., 2000; Kwon and Castillo, 2008a). It is unknown, however, whether MF-PTP is also curtailed in an activitydependent manner.

In the present study we performed whole-cell recordings from CA3 pyramidal neurons in mouse hippocampal slices and mimicked physiologically relevant activity patterns by stimulating GCs with a brief, high-frequency bursting paradigm. To our surprise, MF-PTP was readily observed when the postsynaptic cell was dialyzed with a solution containing high $\mathrm{Ca}^{2+}$ buffering properties, but was nearly absent when the recording solution had a lower, more physiological $\mathrm{Ca}^{2+}$ buffering capacity. These findings strongly suggest that MF-PTP is normally suppressed by a $\mathrm{Ca}^{2+}$-dependent retrograde mechanism. Such negative feedback could not only enable homeostatic regulation of MF-CA3 synaptic strength, ensuring that the essential filtering properties of the connection are maintained during ongoing activity, but also prevent runaway network excitability, as may occur during epileptic activity.

This work supported by National Institutes of Health Grants F32-NS077696 (to S.M.) and R01-DA17392, R01 MH116673, and NIH R01MH125772 (to P.E.C.). S.M. was partially supported by the National Institutes of Health Grant T32-NS007439.

*S.M., S.L., and P.J.L. contributed equally for this work.

D. L. Hunt's present address: Center for Neural Science and Medicine, Cedars-Sinai Medical Center, Los Angeles, CA 90048.

Acknowledgements: We thank all the Castillo lab members for invaluable discussions. We also thank Professor Peter Jonas for his insightful comments on a recent version of our manuscript.

Correspondence should be addressed to Pablo E. Castillo at pablo. castillo@einsteinmed.org.

https://doi.org/10.1523/ENEURO.0450-20.2021

Copyright $@ 2021$ Makani et al.

This is an open-access article distributed under the terms of the Creative Commons Attribution 4.0 International license, which permits unrestricted use, distribution and reproduction in any medium provided that the original work is properly attributed.

\section{Materials and Methods}

\section{Slice preparation}

Animal procedures were approved by our Institutional Animal Care and Use Committee and adhered to National Institutes of Health guidelines. C57BL6 mice of either sex (18-28 d old) were deeply anesthetized with isoflurane, decapitated, and brains rapidly removed and both hippocampi were dissected. Transverse hippocampal slices $(400 \mu \mathrm{m})$ were cut on a DTK-2000 microslicer (Dosaka) or a Leica VT1200 S vibratome, in ice-cold cutting solution containing the following: $215 \mathrm{~mm}$ sucrose, $2.5 \mathrm{~mm} \mathrm{KCl}, 20$ mm glucose, $26 \mathrm{~mm} \mathrm{NaHCO} 3,1.6 \mathrm{~mm} \mathrm{NaH} \mathrm{NO}_{4}, 1 \mathrm{~mm}$ $\mathrm{CaCl}_{2}, 4 \mathrm{~mm} \mathrm{MgSO}_{4}$, and $4 \mathrm{mM} \mathrm{MgCl}_{2}$. After $10 \mathrm{~min}$ of incubation at room temperature, the cutting solution was exchanged for the artificial CSF (ACSF) containing 124 $\mathrm{NaCl}, 2.5 \mathrm{KCl}, 10$ glucose, $26 \mathrm{NaHCO}_{3}, 1 \mathrm{NaH}_{2} \mathrm{PO}_{4}, 2.5$ $\mathrm{CaCl}_{2}$, and $1.3 \mathrm{MgSO}_{4}$. Both cutting and ACSF solutions were saturated with $95 \% \mathrm{O}_{2}$ and $5 \% \mathrm{CO}_{2}(\mathrm{pH} 7.4)$. The slices recovered at room temperature for at least $1.5 \mathrm{~h}$ before recording.

\section{Electrophysiology}

Slices were transferred to a recording chamber and perfused with ACSF (2 ml/min). Recordings were done at $25^{\circ} \mathrm{C}$, except for the experiments included in Figures $1 A$, $6 E-H$, and those that used botulinum toxin-B (BoTX) that were performed at $32^{\circ} \mathrm{C}$. The recording pipette was filled with an internal solution containing the following: $112 \mathrm{~mm}$ K-gluconate, $17 \mathrm{~mm} \mathrm{KCl,} 0.04 \mathrm{~mm} \mathrm{CaCl}_{2}, 10 \mathrm{~mm}$ HEPES, $2 \mathrm{~mm} \mathrm{Mg}$-ATP, $0.2 \mathrm{~mm}$ GTP, $10 \mathrm{~mm} \mathrm{NaCl}$, and $0.1 \mathrm{~mm}$ EGTA (pH 7.2; 290-295 mOsm). For the experiments using $10 \mathrm{~mm}$ EGTA or BAPTA, the concentration of K-gluconate was reduced to compensate for osmolarity. The pipette resistance ranged from 3 to $4 \mathrm{M} \Omega$. Series resistance (6-15 $\mathrm{M} \Omega$ ) was monitored throughout the experiment, and those experiments in which the series resistance changed by $>10 \%$ were not included for analysis. Patch pipettes were pulled on a PP-830 vertical puller (Narishige).

Responses were generated by stimulating presynaptic axons and recording from CA3 pyramidal neurons. Kainate receptor (KAR) responses were recorded in the presence of GYKI-53655 (30 $\mu \mathrm{M})$ or LY $303070(15 \mu \mathrm{M})$, and CGP-55845 (3 $\mu \mathrm{M})$ in the bath, and MK-801 (2 mM) in the pipette. With the exception of data obtained in Figures $1 A, 6 E-H$; Extended Data Figure 5-1C, AMPA receptor (AMPAR)-mediated responses were also generated with MK-801 in the pipette, and GYKI-53655 (1 $\mu \mathrm{M})$ in the bath (Kwon and Castillo, 2008a). NMDA receptor (NMDAR) responses were recorded with NBQX $(10 \mu \mathrm{M})$ in the bath. All experiments except those in Figures $1 A, C, 6 E-H$ contained picrotoxin $(100 \mu \mathrm{M})$.

KAR and NMDAR-mediated EPSCs were evoked by placing a monopolar stimulating pipette with a broken tip $(\sim 5-10 \mu \mathrm{m}$ in diameter, filled with ACSF) in the dentate gyrus (DG) cell body layer. For AMPAR-mediated responses, the tip was left unbroken $(\sim 1 \mu \mathrm{m})$ to minimize the number of MFs activated. For minimal stimulation experiments, a theta-glass stimulating pipette was placed in 
A

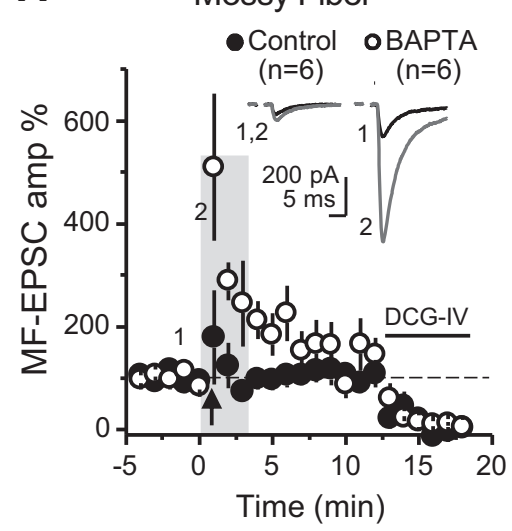

B Associational-Commissural

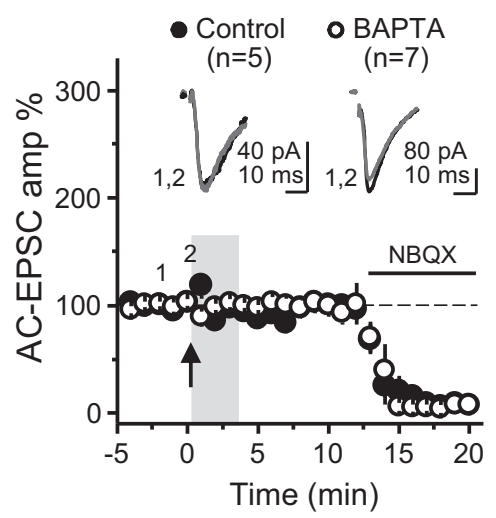

D
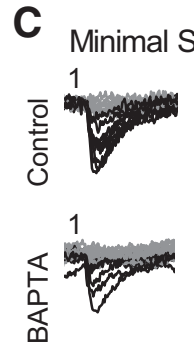

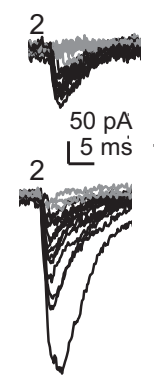

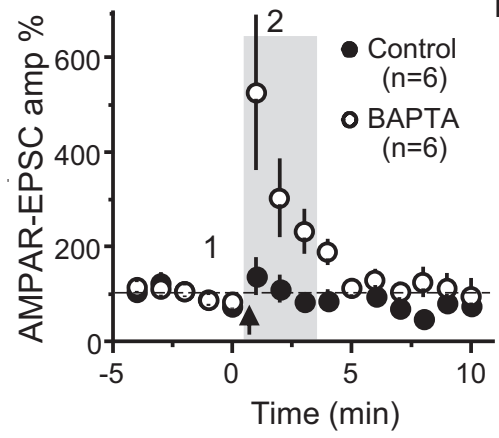

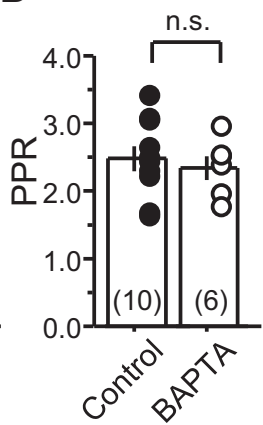

Figure 1. High postsynaptic $\mathrm{Ca}^{2+}$ buffering selectively enhances PTP at the MF-CA3 synapse. $\boldsymbol{A}$, Summary data showing the effect of loading the patch pipette with $10 \mathrm{~mm}$ BAPTA on PTP of AMPAR-mediated MF-responses compared with control condition (0.1 mM EGTA; control: $125 \pm 52 \%$ of baseline; $n=6$; BAPTA: $347 \pm 84 \% ; n=6$; control vs BAPTA: $p<0.05)$. Experiments were performed at $32^{\circ} \mathrm{C}, \mathrm{Vh}=-60 \mathrm{mV}$, with only a low concentration of the AMPAR selective antagonist GYKI-53655 (1 $\left.\mu \mathrm{M}\right)$, and the bursting paradigm was performed in current-clamp mode. AMPAR-EPSCs were evoked with bulk stimulation in the GC layer. At the end of the experiments, DCG-IV $(1 \mu \mathrm{M})$ was added to the bath to verify that the synaptic responses were mediated by MF activation. PTP is quantified as the average of the EPSCs during the first 3 min postinduction versus the 3-min prior induction. Representative traces (top) and time course summary plot (bottom). B. Summary data of experiments in which the same bursting paradigm was performed at the neighboring associational-commissural (CA3-CA3) synapse. Note no difference between control and BAPTA-dialyzed cells (control: $101 \pm 6 \% ; n=5$; BAPTA: $95 \pm 3 \%$; $n=7$; control vs BAPTA: $p>0.3$ ). NBQX was used at the end of the experiments to confirm AMPAR-mediated responses. $\boldsymbol{C}$, PTP assessed by minimal stimulation of MFs while monitoring AMPAR-EPSCs in the absence of drugs in the bath. PTP was induced in current-clamp mode. Left, Representative traces showing successes (black) and failures (gray). Right, Summary data showing MF-PTP elicited with minimal stimulation in control and BAPTA-dialyzed cells (control: $112 \pm 27$ of baseline; $n=6$; BAPTA: $354 \pm 82 ; n=6$; control vs BAPTA: $p<0.05$ ). Gray box indicates the 3-min post-PTP time window quantified for comparison in control and BAPTA conditions in all experiments. $\boldsymbol{D}$, PPR was not affected by intracellular 10 mM BAPTA loading (control: $2.5 \pm 0.18 ; n=10$; BAPTA: $2.3 \pm 0.17 ; n=6$; control vs BAPTA: $p>0.5$ ). Number of cells are indicated between brackets. Here and in all figures, data are presented as mean \pm SEM; representative traces correspond to the time points indicated by numbers on the time course plots. n.s., non-significant.

stratum lucidum $100 \mu \mathrm{m}$ away from the recorded CA3 pyramidal cell. Intensity was increased until a success/failure pattern of AMPAR-EPSC responses was observed. MF AMPAR-EPSCs were only accepted for analysis if the following criteria were met: robust PPF (at least 2fold), DCG-IV sensitivity $>85 \%$, fast rise time (10-90\%) was $<1.2 \mathrm{~ms}$, response onset was $<5.0 \mathrm{~ms}$, and these values did not significantly change after the bursting. These criteria were based on those established by previous studies of MF-CA3 transmission (Jonas et al., 1993). To record KAR-EPSCs and AMPAR-EPSCs, cells were voltage-clamped at $-60 \mathrm{mV}$. For NMDAR-EPSCs, cells were held at $-50 \mathrm{mV}$. Unless otherwise stated, baseline NMDAR-EPSCs and KAR-EPSCs were obtained by delivering two stimuli separated by $5 \mathrm{~ms}$ to evoke a measurable response (Weisskopf and Nicoll, 1995). Stimulus intensity for KAR/NMDAR-mediated and AMPAR-mediated responses was $\sim 100$ and $10 \mu \mathrm{A}$, respectively. Stimulus intensities did not differ, on average, between control and BAPTA-dialyzed cells in any given condition. Stimulus duration was 100-200 $\mu$ s. CA3 neurons were always dialyzed for $\geq 15 \mathrm{~min}$, while stimulating at $0.1 \mathrm{~Hz}$, before delivering any plasticity-inducing stimulation. For synaptically evoked action potentials (Fig. 6E-H), no drugs were bath applied and CA3 pyramidal cells were held in current-clamp mode before, during and after the induction. Resting potential was kept between -60 and $-75 \mathrm{mV}$. Baseline and postinduction spiking probability 
were measured as the average of number of spikes per burst normalized to the number of pulses per burst. (i.e., three pulses at $25 \mathrm{~Hz}$ ).

The baseline stimulation frequency for all experiments was $0.1 \mathrm{~Hz}$, except for frequency facilitation (five stimuli, $25 \mathrm{~Hz}$ ), which was delivered at $0.05 \mathrm{~Hz}$. The standard PTP induction protocol consisted of 25 bursts (five stimuli, $50 \mathrm{~Hz}$ ) delivered at $2 \mathrm{~Hz}$. PTP was never generated more than once in a given slice. To achieve a similar time course of potentiation in BAPTA-dialyzed cells when the interstimulus interval was $40 \mathrm{~ms}$ (Fig. $3 C$ ), or when monitoring MF AMPAR-mediated transmission (Figs. $1 A, 3 B$ ), it was necessary to use 50 bursts. The bursting induction protocol was delivered while cells were voltage-clamped at $-60 \mathrm{mV}$, except for the experiments included in Figures $1 A, C, 2 C, 6 E-H$, in which PTP was induced in current-clamp. Long-term potentiation (LTP) in CA1 pyramidal neurons was induced by pairing postsynaptic depolarization from -60 to $0 \mathrm{mV}$ for 3 min with low-frequency stimulation of Schaffer collaterals (180 pulses, $2 \mathrm{~Hz}$ ).

In all experiments examining MF synaptic transmission, the mGluR2/3 agonist DCG-IV (1-2 $\mu \mathrm{M})$ was applied at the end of the experiment and data were included only when the response was inhibited by $>85 \%$. For perforated patch experiments, nystatin was first dissolved into DMSO $(10 \mathrm{mg} / \mathrm{ml})$. This was then diluted 250 -fold into the intracellular solution to yield $40 \mu \mathrm{g} / \mathrm{ml}$. BoTX was prepared by making a $0.5 \mu \mathrm{m}$ stock solution with $1 \mathrm{mg} / \mathrm{ml}$ BSA. This was then diluted 100 -fold into the final intracellular solution, with $0.5 \mathrm{~mm}$ DL-dithiothreitol (DTT).

\section{Reagents}

MK-801, NBQX, CGP-55845, nimodipine, DCG-IV, and GYKI 53655 were obtained from Tocris-Cookson. LY 303070 was obtained from $A B X$ advanced biochemical compounds. BoTX was obtained from List Biological. All other chemicals and drugs were purchased from Sigma-Aldrich.

\section{Data analysis}

Experiments were executed with a MultiClamp 700B amplifier (Molecular Devices). Data were analyzed online using IgorPro (Wavemetrics), and offline with Origin 9.2 and GraphPad Prism. The 3 min before the induction protocol was used as a baseline for statistics. Following the protocol, the first 3 min were used to calculate PTP in all experiments of the study, and the last $3 \mathrm{~min}$ (of a $30 \mathrm{~min}$ period) for the positive control experiment testing LTP at the Schaffer collateral to CA1 pyramidal cell synapse (Extended Data Fig. 5-1C). Representative responses are averages of 18 traces. All values are shown as mean \pm SEM. Unless otherwise stated, Student's $t$ test was used for statistical significance between two samples, and ANOVA for multiple comparisons. Data that did not display a normal distribution using the Shapiro-Wilk test were compared using the non-parametric test MannWhitney and Wilcoxon signed-ranked test for unpaired and paired conditions respectively. All experiments for a given condition were performed in an interleaved fashion,
A

O 10 mM BAPTA $(n=7)$

B $10 \mathrm{mM} \mathrm{EGTA}(\mathrm{n}=6)$

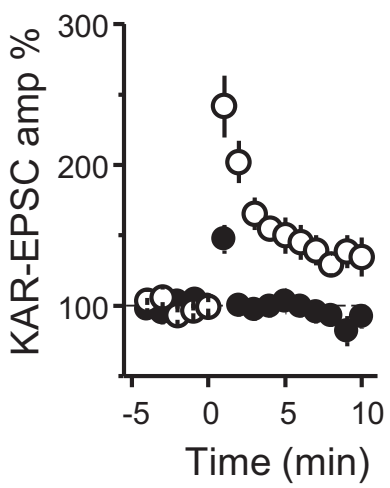

Control $(n=7)$

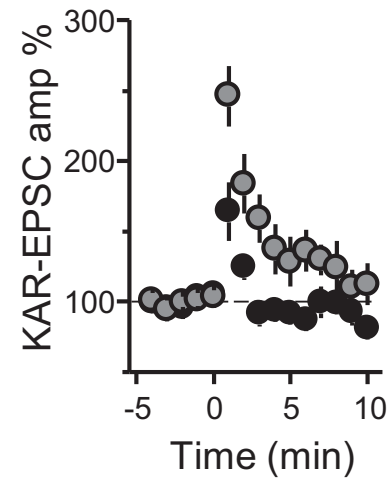

C
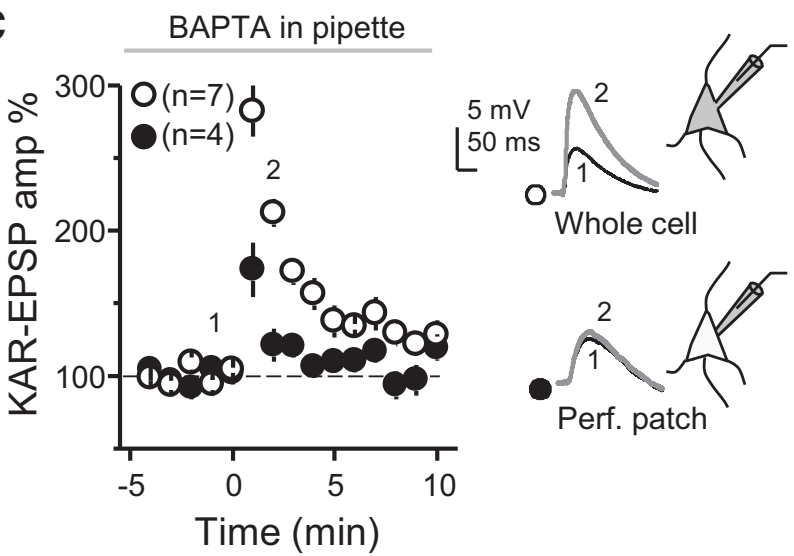

Figure 2. Weak MF-PTP of KAR-mediated transmission under physiological postsynaptic $\mathrm{Ca}^{2+}$ buffering recording conditions. $\boldsymbol{A}$, Summary data showing the effect of $10 \mathrm{~mm}$ BAPTA on MFPTP (control: $115 \pm 6 \% ; n=6$; BAPTA: $203 \pm 14 \% ; n=7$; control vs BAPTA: $p<0.001)$. $\boldsymbol{B}$, Summary data for control versus 10 mM EGTA (control: $122 \pm 13 \%, n=7 ; 10$ mM EGTA: $196 \pm 17 \%$ of baseline, $n=6$; control vs $10 \mathrm{~mm}$ EGTA $p<0.01)$. C, left, Summary effect when $10 \mathrm{~mm}$ BAPTA was included in the recording pipette, in whole-cell versus perforated-patch configuration (BAPTA perforated patch: $138 \pm 11 \%$; $n=7$; BAPTA whole-cell: $226 \pm 11 \%$; $n=4$; BAPTA perforated patch vs BAPTA whole-cell: $p<0.001)$. Right, EPSPs from representative experiments. See Extended Data Figure 2-1 for supporting information.

i.e., control experiments were performed for every test experiment.

\section{Results}

\section{MF PTP is minimal under physiological postsynaptic $\mathrm{Ca}^{2+}$ buffering conditions}

This study was initiated by the unexpected observation that MF-PTP magnitude was highly dependent on the postsynaptic $\mathrm{Ca}^{2+}$ buffering conditions. We induced MFPTP by activating MFs with a bursting protocol ( 25 bursts delivered at $2 \mathrm{~Hz}$; five stimuli at $50 \mathrm{~Hz}$ within a burst) designed to mimic physiological activity patterns of GCs in vivo (Henze et al., 2002; Pernía-Andrade and Jonas, 2014; 
Diamantaki et al., 2016; GoodSmith et al., 2017; Senzai and Buzsáki, 2017), while monitoring AMPAR-EPSCs (see Materials and Methods) under physiological recording conditions, e.g., no drugs in the bath, near-physiological recording temperature $\left(32^{\circ} \mathrm{C}\right)$ and voltage clamping at resting membrane potential (chloride reversal potential). The PTP induction protocol was delivered in currentclamp configuration so that CA3 cells were able to fire freely. To our surprise, we did not observe much potentiation when postsynaptic CA3 pyramidal cells were loaded with 0.1 mM EGTA, a near physiological intracellular $\mathrm{Ca}^{2+}$ buffering condition that we refer to as "control," but saw robust MF-PTP with $10 \mathrm{~mm}$ BAPTA in the postsynaptic pipette (Fig. 1A). In contrast, BAPTA did not increase PTP of associational-commissural (AC) synaptic responses (Fig. 1B). These results are consistent with previous studies that reported little potentiation at the AC synapse (Salin et al., 1996), and suggest that the robust PTP unmasked in BAPTA-dialyzed cells is specific to the MFCA3 synapse. Importantly, the enhancement of MF-PTP under high postsynaptic $\mathrm{Ca}^{2+}$ buffering conditions was also observed with minimal stimulation of MFs (Jonas et al., 1993; Fig. 1C), indicating that the PTP enhancement is not an artifact of strong extracellular stimulation. Lastly, we found that $10 \mathrm{~mm}$ BAPTA did not affect the basal paired-pulse ratio (PPR; i.e., before bursting; Fig. 1D), making unlikely that changes in basal Pr could account for the PTP enhancement. These initial observations suggested that MF-PTP, a phenomenon widely believed to be presynaptic in nature, was under the control of a postsynaptic $\mathrm{Ca}^{2+}$-dependent process that deserved further investigation.

A major problem when studying MF-CA3 synaptic plasticity is the polysynaptic contamination associated with extracellular stimulation of MFs (Claiborne et al., 1993; Henze et al., 2000; Nicoll and Schmitz, 2005; Kwon and Castillo, 2008a). Repetitive stimulation aggravates this problem as MF-CA3 synapses can be potentiated several-fold by strong frequency facilitation (Regehr et al., 1994; Salin et al., 1996). To rule out the possibility that the PTP was the result of polysynaptic contamination, we blocked AMPA and NMDAR-mediated transmission, and monitored KAR-EPSCs, which are observed at MF-CA3 synapses but not AC-CA3 synapses (Castillo et al., 1997). When CA3 pyramidal neurons were loaded with $10 \mathrm{~mm}$ BAPTA the burst stimulation protocol caused a robust PTP of KAR-mediated transmission as compared with control (0.1 mм EGTA; Fig. 2A). To discard that PTP suppression could result from some unexpected effect of BAPTA, we repeated our experiments with $10 \mathrm{~mm}$ EGTA, a slow $\mathrm{Ca}^{2+}$ chelator that is widely used at this concentration in voltage-clamp recordings. MF-PTP was equally robust in $10 \mathrm{~mm}$ EGTA-loaded cells (Fig. 2B; Extended Data Fig. 2-1A,B). To ensure fast postsynaptic $\mathrm{Ca}^{2+}$ chelation, subsequent experiments compared cells loaded with 0.1 mM EGTA versus $10 \mathrm{~mm}$ BAPTA. Lastly, we verified that KAR-EPSC and AMPAR-EPSC amplitudes in control and BAPTA-loaded cells were comparable (Extended Data Fig. 2-1C) and that MF-PTP in BAPTA cells returned to baseline 20 min postinduction (Extended Data Fig. 2-1D).
Collectively, these findings demonstrate that postsynaptic $\mathrm{Ca}^{2+}$ buffering had a striking influence on the magnitude of MF-PTP.

One interpretation of the set of observations above is that CA3 pyramidal neurons normally have high $\mathrm{Ca}^{2+}$ buffering capacity (i.e., similar to $10 \mathrm{~mm}$ EGTA), and replacing these with the $0.1 \mathrm{~mm}$ EGTA solution somehow abolished PTP. To directly address this possibility, we monitored KAR-EPSPs with BAPTA in the recording pipette, in perforated patch versus whole-cell configuration. In perforated patch conditions, in which BAPTA could not diffuse into the cell, only a small amount of PTP was seen, while KAR-EPSPs in whole-cell mode displayed similar striking potentiation observed above when KAR-EPSCs were recorded from BAPTA-loaded cells (Fig. 2C, see also Fig. $2 A)$. These results indicate that the endogenous $\mathrm{Ca}^{2+}$ buffering capacity of $\mathrm{CA} 3$ pyramidal neurons was functionally more similar to the $0.1 \mathrm{~mm}$ EGTA solution than to the 10 mM BAPTA solution.

We next confirmed the MF-PTP observed in BAPTA conditions was presynaptic in nature. If this PTP was presynaptic, it should be similarly observed when monitoring KAR-EPSCs, NMDAR-EPSCs and AMPAR-EPSCs (unlike the data reported in Fig. 1A, AMPAR-EPSCs in these experiments were pharmacologically isolated and recorded under conditions of low network excitability; see Materials and Methods). Indeed, when either NMDAR-mediated or AMPAR-mediated EPSCs were monitored, little to no potentiation was observed in control conditions, but the response was markedly increased in BAPTA (Fig. $3 A, B$ ). Notably, there was no difference when comparing the PTP magnitude of control cells in KAR, AMPAR, and NMDAR groups to each other (ANOVA; $F=1.76 ; p>0.2$, $\mathrm{df}=15$ ), or when comparing the BAPTA-dialyzed cells in the three receptor groups to each other (ANOVA; $F=0.74$; $p>0.4, \mathrm{df}=17$ ). Thus, the difference in PTP between control and BAPTA persisted regardless of which postsynaptic receptor was pharmacologically isolated. To assess changes in PPR, we monitored KAR-mediated responses. Here, the induction was accompanied by a greater reduction in PPR in BAPTA-dialyzed cells, consistent with an increase in Pr. Importantly, in both control and BAPTA-dialyzed cells, the recovery time course of EPSC amplitude and PPR mirrored each other (Fig. $3 C$ ), suggestive of a causal relationship between presynaptic $\operatorname{Pr}$ and the postsynaptic response magnitude. Together, these independent lines of evidence confirm a presynaptic locus of MFPTP in BAPTA-dialyzed cells. Again, as for AMPAREPSCs (Fig. 1D), no significant difference was noted in the degree of basal PPR (i.e., before bursting) between control and BAPTA-dialyzed cells (control: $2.4 \pm 0.2$; $n=25$; BAPTA $2.7 \pm 0.2 ; n=27$; control vs BAPTA $p>0.2$; data not shown), supporting the notion that postsynaptic BAPTA loading did not affect basal Pr. The most parsimonious explanation for a robust presynaptic potentiation being unmasked by preventing a rise in postsynaptic $\mathrm{Ca}^{2+}$ is a retrograde signal that suppresses potentiation in normal conditions. This interpretation is consistent with the fact that most forms of retrograde signaling so far described require a rise in postsynaptic $\mathrm{Ca}^{2+}$ concentration (Fitzsimonds and Poo, 1998; Regehr et al., 2009). 

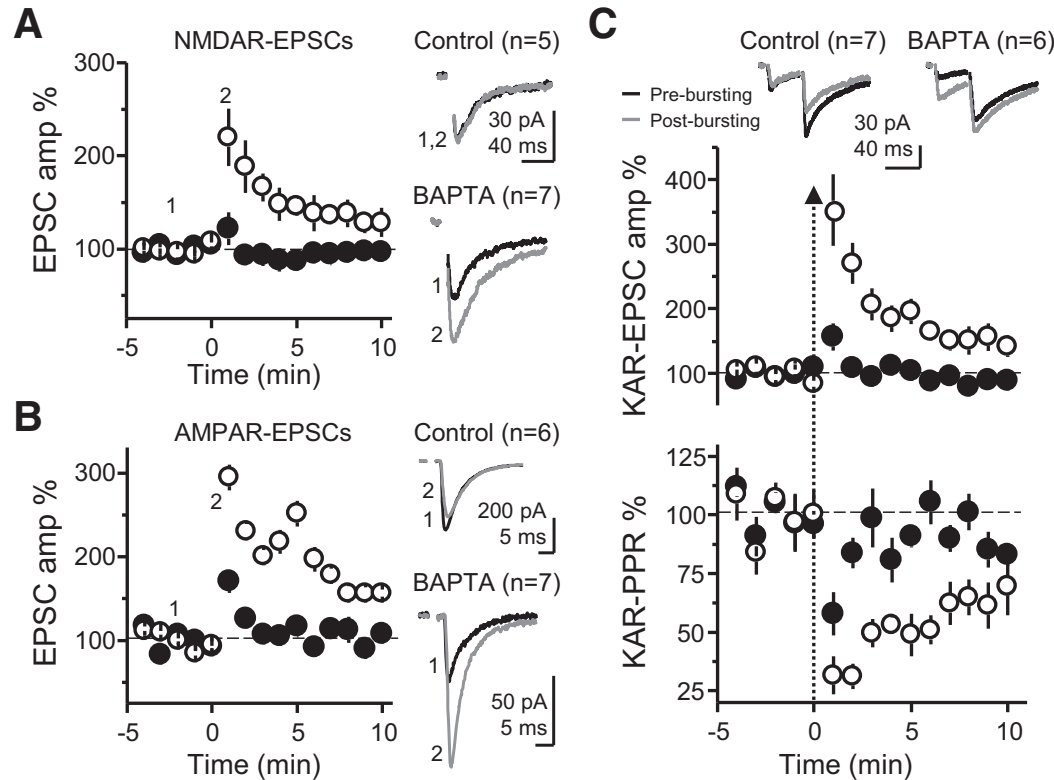

Figure 3. Enhanced MF-PTP by high postsynaptic $\mathrm{Ca}^{2+}$ buffering capacity is presynaptically expressed. $\boldsymbol{A}$, Summary data showing the effect of 25 bursts on NMDAR-mediated EPSCs $\left(\mathrm{V}_{\mathrm{H}}=-50 \mathrm{mV}\right)$, when CA3 neurons were dialyzed with control versus BAPTA intracellular solution (control: $102 \pm 11 \%$ of baseline; $n=5$; BAPTA: $191 \pm 23 \% ; n=7$; control vs BAPTA: $p<0.05$ ). $\boldsymbol{B}$, Summary plot of the AMPAR-mediated MF response after the bursting paradigm, in control versus BAPTA conditions (control: $135 \pm 17 \% ; n=6$; BAPTA: $223 \pm 16 \% ; n=7$; control vs BAPTA: $p<0.01)$. $\boldsymbol{C}$, KAR PPR was monitored by delivering two pulses (40-ms interstimulus interval). Top, Averaged traces from representative experiments, before and after bursting, and summary plot of the first EPSC amplitude in control versus BAPTA solutions. Bottom, Summary of PPR time course as normalized to the 3 min before the bursting paradigm. Same cells as in top panel (control: $80 \pm 8 \% ; n=7$; BAPTA: $37 \pm 5 \% ; n=6$; control vs BAPTA: $p<0.01$ ).

\section{Source of postsynaptic $\mathrm{Ca}^{2+}$ rise involved in PTP suppression}

We next sought to assess the source or sources of the postsynaptic $\mathrm{Ca}^{2+}$ rise involved in the suppression of MF-PTP. $\mathrm{Ca}^{2+}$ influx via NMDARs, or $\mathrm{Ca}^{2+}$-permeable AMPARs or KARs, was ruled out as solely sufficient for retrograde suppression, given that pharmacological blockade of these receptors did not unmask PTP (Figs. 2, 3A). Several voltage-gated $\mathrm{Ca}^{2+}$ channels (VGCCs) exist in the thorny excrescence of CA3 pyramidal neurons (Kapur et al., 2001; Reid et al., 2001). Since the thorny excrescences in our experiments could have been poorly voltage-clamped (at $-60 \mathrm{mV}$ ) during the induction protocol, one or more of these channels may have contributed to the rise in postsynaptic $\mathrm{Ca}^{2+}$. To address this possibility, we added nimodipine $(10 \mu \mathrm{M})$ to the bath solution to ensure L-type VGCCs were blocked in this experiment. If L-type channels were in fact the source of the $\mathrm{Ca}^{2+}$ required for the putative retrograde suppression, we would expect that blocking those channels would mimic the effect of BAPTA, and that both control and BAPTA-dialyzed cells exhibit robust PTP. However, under these recording conditions, a large difference between control and BAPTA-dialyzed cells remained (Fig. $4 A$ ), suggesting that L-type channels do not contribute significantly to the regulation of MF-PTP. We next examined the potential role of R-type and T-type VGCCs by adding $100 \mu \mathrm{M} \mathrm{Ni}^{2+}$. Under these recording conditions, and likely because of the blockade of presynaptic R-type channels, as previously reported (Breustedt et al., 2003; Dietrich et al., 2003), MF-PTP was dampened, but the difference between low and high postsynaptic $\mathrm{Ca}^{2+}$ buffering conditions remained (Fig. 4B). Intriguingly, MF-PTP in the presence of $\mathrm{Ni}^{2+}$ and nimodipine was followed by synaptic depression, but intracellular BAPTA was still able to enhance PTP. It is therefore unlikely that R-type and Ttype VGCCs in CA3 pyramidal neurons contribute significantly to MF-PTP suppression.

To investigate the potential role of intracellular $\mathrm{Ca}^{2+}$ stores, we included cyclopiazonic acid (CPA; $30 \mu \mathrm{m}$ ) in the patch pipette to deplete $\mathrm{Ca}^{2+}$ from the endoplasmic reticulum. CPA led to an increase in MF-PTP relative to control cells (Fig. $4 C$ ), suggesting that the rise in $\mathrm{Ca}^{2+}$ required by the retrograde signal is mediated, at least partially, by intracellular stores. CPA could have diffused from the recorded cell to the presynaptic terminal, reduced $\mathrm{Pr}$, and thereby increased the magnitude of PTP. To address this possibility, we delivered a synaptic burst (five pulses, $25 \mathrm{~Hz}$ ) to cells loaded with control solution, and those loaded with CPA. There was no difference between the ratio of the fifth/first KAR-EPSC amplitude (control: $7.5 \pm 1.7 ; n=5$; CPA: $6.9 \pm 1.2 ; n=5 ; p>0.5$; data not shown), suggesting no difference in Pr. Thus, the increase in PTP seen in CPA-loaded cells was likely because of depletion of postsynaptic $\mathrm{Ca}^{2+}$ stores. Lastly, release of $\mathrm{Ca}^{2+}$ from internal stores can be triggered by activation of inositol 1,4,5-trisphosphate receptors $\left(\mathrm{IP}_{3} \mathrm{Rs}\right.$; Verkhratsky, 2005), a signaling pathway that has been shown to underlie $\mathrm{Ca}^{2+}$ rises in $\mathrm{CA} 3$ 
A
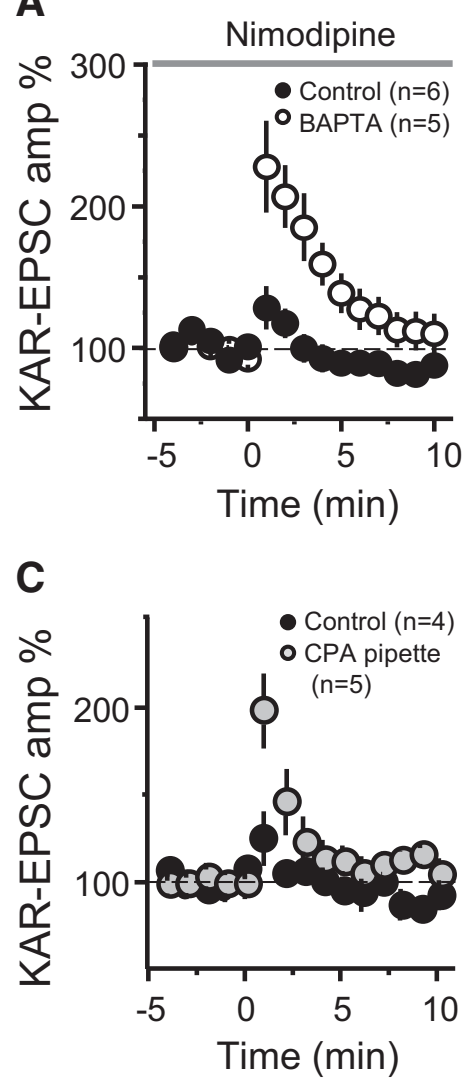

B

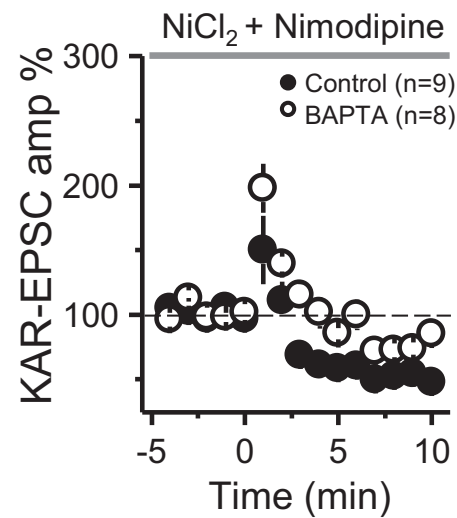

D

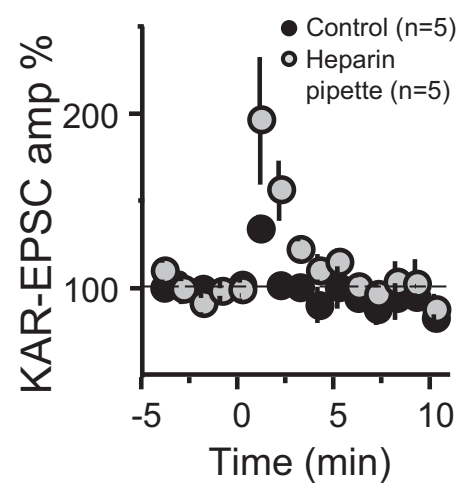

Figure 4. Suppression of MF-PTP depends on internal $\mathrm{Ca}^{2+}$ stores. $\boldsymbol{A}$, Summary effect of $10 \mu \mathrm{M}$ nimodipine in the bath in control and BAPTA-dialyzed cells (control: $115.24 \pm 9.9 \% ; n=6$; BAPTA: $201.31 \pm 27.8 \% ; n=5$; control vs BAPTA: $p<0.05$ ). B, Summary effect of adding $100 \mu \mathrm{M} \mathrm{Ni}{ }^{2+}$ and $10 \mu \mathrm{m}$ nimodipine to the bath (control: $110 \pm 14 ; n=9$; BAPTA: $151 \pm 9$; $n=8$; control vs BAPTA: $p<0.05$ ). $\boldsymbol{C}$, Summary effect of including CPA in the patch pipette (control: $112 \pm 6 \% ; n=4$; CPA: $156 \pm 16 \%$; $n=5$; control vs CPA: $p<0.05$ ). $\boldsymbol{D}$, Summary effect of including heparin in the recording pipette to block $\mathrm{IP}_{3} \mathrm{Rs}$ (control: $112 \pm 2 \%$; $n=5$; heparin: $157 \pm 17 \% ; n=5$; control vs heparin: $p<0.05$ ).

pyramidal neurons (Kapur et al., 2001) and postsynaptic plasticity (Kwon and Castillo, 2008b) at the MF-CA3 synapse. To examine whether $\mathrm{IP}_{3} \mathrm{Rs}$ played a role in the suppression of MF-PTP, we included heparin $(2.5 \mathrm{mg} /$ $\mathrm{ml}$ ) in the patch pipette. With $\mathrm{IP}_{3}$ Rs blocked, PTP was increased to a similar level as when cells were loaded with CPA (Fig. 4D). Together, these results suggest that $\mathrm{IP}_{3} \mathrm{R}$-triggered release from internal $\mathrm{Ca}^{2+}$ stores contributes to the suppressive effect on PTP.

\section{Assessing the mechanism underlying MF-PTP suppression}

One way that the release of $\mathrm{Ca}^{2+}$ from internal stores can be triggered is via activation of Group I mGluRs (i. e., mGluR1 and mGluR5 subtypes). These G-proteincoupled receptors (GPCRs) are likely activated during our PTP induction protocol and have been shown to mobilize $\mathrm{Ca}^{2+}$ stores at the MF-CA3 synapse (Kapur et al., 2001). However, with the mGluR5 antagonist MPEP $(4 \mu \mathrm{M})$ and the mGluR1 antagonist CPCCOEt $(100 \mu \mathrm{M})$ in the bath solution, a large difference remained between the potentiation observed in control and BAPTA-dialyzed cells (Fig. $5 A$ ), whereas in separate experiments we found these antagonists greatly reduced the inward current induced by the Group I mGluR agonist DHPG (Extended Data Fig. 5-1A). To test for the potential involvement of other GPCRs in mobilizing $\mathrm{Ca}^{2+}$ from internal stores (e.g., by activating $I_{3} R$ s), we used GDP$\beta S(1 \mathrm{~mm})$, a nonhydrolyzable GDP analog that interferes with G-protein signaling. Including GDP- $\beta$ S in the recording pipette solution had no apparent effect on the retrograde suppression as we observed significantly less MF-PTP in control compared with BAPTA-dialyzed cells (Fig. 5B). As positive control, we found that intracellularly loaded GDP- $\beta S$ in CA3 pyramidal neurons abolished the outward current induced by the $\mathrm{GABA}_{\mathrm{B}} \mathrm{R}$ agonist baclofen (50 $\mu \mathrm{m}$; Extended Data Fig. 5-1B). Together, these results suggest that mobilization of the putative retrograde signal that suppresses MF-PTP requires $\mathrm{IP}_{3} \mathrm{R}$-mediated release of $\mathrm{Ca}^{2+}$ from internal stores, but is independent from the activation of Group I mGluRs or other GPCR-dependent signaling, although we cannot rule out the possibility that G-protein-independent signaling could be involved (Gerber et al., 2007).

Dendrites on postsynaptic neurons have been shown to release retrograde messengers consisting of lipids, 
A

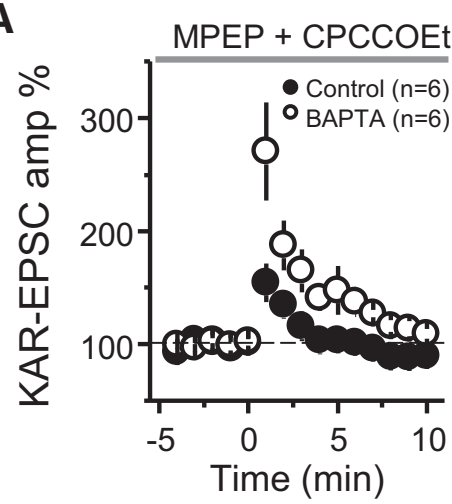

C

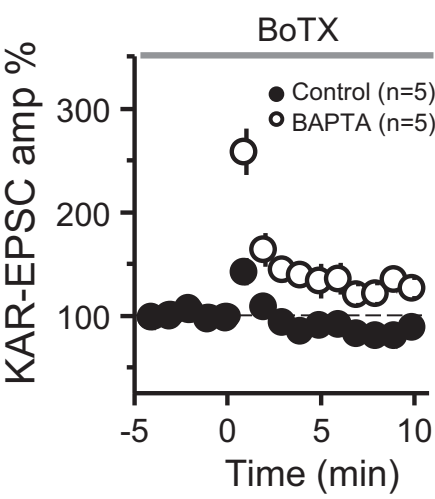

E

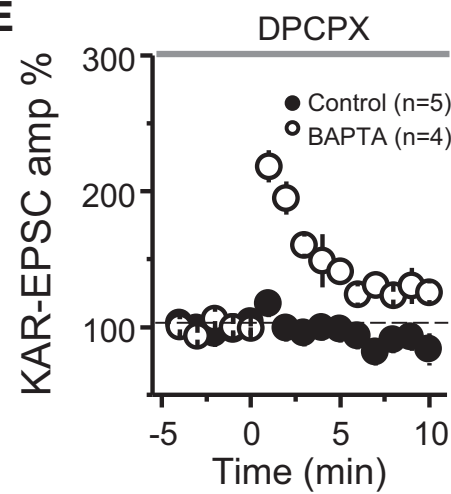

B

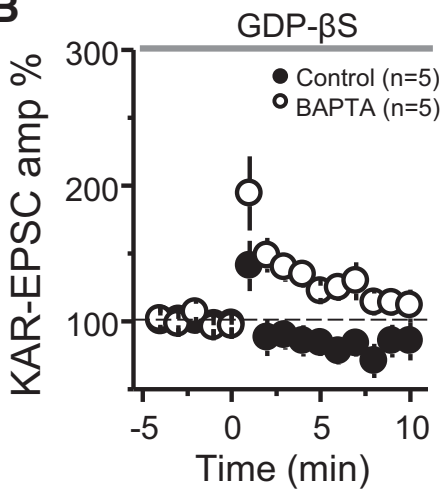

D
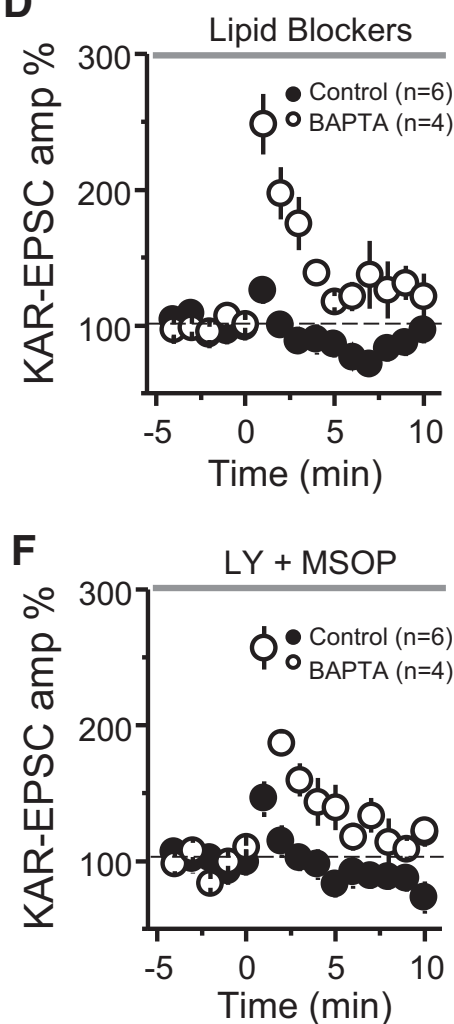

Figure 5. Assessing the mechanism underlying MF-PTP suppression. $\boldsymbol{A}$, Summary of data of MF-PTP under control (0.1 mM EGTA) and high intracellular buffering conditions (10 mM BAPTA) in the presence of the Group I mGluR antagonists MPEP and CPCCOEt (control: $122 \pm 6 \% ; n=6$; BAPTA: $208 \pm 28 \% ; n=6$; control vs BAPTA: $p<0.05$ ). $B$, Summary data of experiments in which control and BAPTA cells were dialyzed with GDP- $\beta$ S (control-GDP- $\beta$ S: $106 \pm 13 \%$; $n=5$; BAPTA-GDP- $\beta$ S: $161 \pm 17 \%$; $n=5$; controlGDP- $\beta$ S vs BAPTA-GDP- $\beta$ S: $p<0.05)$. $\boldsymbol{C}$, Cells dialyzed with BoTX did not exhibit any more PTP than interleaved controls without BoTX (BoTX included in control solution: $116 \pm 2 \% ; n=5$; BAPTA without BoTX: $189 \pm 16 \%$; $n=5$; control-BoTX vs BAPTA: $p<0.01)$. $\boldsymbol{D}$, Summary data when a cocktail of lipid blockers (ETYA, indomethacin, and RHC-80267) was included in the intracellular recording solution (control: $105 \pm 6 \%$ of baseline; $n=6$; BAPTA: $220 \pm 21 \% ; n=4$; control vs BAPTA: $p<0.001$ ). $\boldsymbol{E}$, Summary data showing no PTP in control cells after bursting paradigm in the presence of the adenosine 1 receptor antagonist DPCPX, whereas robust PTP observed in BAPTA-dialyzed cells (control: $104 \pm 3 \% ; n=5$; BAPTA: $191 \pm 7 \%$; $n=4$; control vs BAPTA: $p<0.001$ ). $\boldsymbol{F}$, Summary data showing the effect of bursting paradigm in control and BAPTA-dialyzed cells in the presence of the Group II and III mGluR antagonists LY-341495 and MSOP (control: $121 \pm 10 \% ; n=6$; BAPTA: $201 \pm 10 \%$; $n=4$; control vs BAPTA: $p<0.001$ ). See Extended Data Figure 5-1 for supporting information.

gases, peptides, growth factors, and conventional neurotransmitters (Regehr et al., 2009), some of which are released by SNARE-dependent exocytosis. To test whether the putative retrograde signaling suppressing MF-PTP involves vesicular release, we used BoTX, which cleaves synaptobrevin-2, thus eliminating SNARE-dependent exocytosis (Schiavo et al., 2000; Montal, 2010). Adding BoTX (5 nm) to the intracellular solution did not enhance MF-PTP (Fig. 5C). In separate, interleaved experiments that served as a positive control, and as previously 
reported (Lledo et al., 1998), we found that loading BoTx into CA1 pyramidal neurons blocked LTP of AMPAR-mediated transmission (see Materials and Methods; Extended Data Fig. 5-1C). These findings argue against SNARE-dependent exocytosis in mediating the putative retrograde signal involved in MF-PTP suppression.

We next examined whether lipids mediate MF-PTP suppression. For instance, endocannabinoids, perhaps the most characterized retrograde signals in the brain (Kano et al., 2009; Castillo et al., 2012), suppress PTP at the parallel fiber-Purkinje cell synapse in the cerebellum by activating presynaptic type 1 cannabinoid receptors (Beierlein et al., 2007). However, these receptors are not expressed at the MF-CA3 synapse in mature animals (Marsicano and Lutz, 1999; Katona et al., 2006; Hofmann et al., 2008; Caiati et al., 2012). To test whether a different lipid signal acting as a retrograde signal, such as arachidonic acid (AA; Carta et al., 2014), or the AA metabolite 12-(S)-HPETE (Feinmark et al., 2003), could suppress MF-PTP, we added a cocktail of inhibitors to the patch pipette solution to inhibit $A A$ and other components of lipid synthesis in the postsynaptic neuron. We included eicosatetraynoic acid (ETYA; 100 $\mu \mathrm{M})$ and indomethacin $(10 \mu \mathrm{M})$ to inhibit lipoxygenases and cyclooxygenases (COX 1 and 2), enzymes that catalyze the metabolism of eicosanoids and prostanoids, respectively. We also added RHC-80267 (50 $\mu \mathrm{M})$ to inhibit diacylglycerol (DAG) lipase. With this combination of lipid inhibitors in the pipette, we continued to see robust MF-PTP in BAPTA-dialyzed cells, but none when the cocktail was included in control cells (Fig. 5D). Our results suggest that the putative retrograde signal that suppressed PTP at the MF-CA3 synapse does not depend on these lipid-derived pathways.

Lastly, we explored potential ways by which glutamate release was suppressed during PTP. Presynaptic type 1 adenosine receptors (A1Rs) can tonically inhibit glutamate release at this synapse (Moore et al., 2003; but see Kukley et al., 2005). To test whether these receptors mediate MFPTP suppression, we used the A1R-selective antagonist DPCPX (200 nM). DPCPX did not alter the robust difference in PTP observed in control versus BAPTA-dialyzed cells (Fig. $5 E$ ), but significantly increased the amplitude of MF KAR-EPSCs (Extended Data Fig. 5-1D), indicating that DPCPX was active and therefore, A1Rs were not underlying the suppression of MF-PTP. Glutamate release from MFs is also blocked by the activation of presynaptic Group II/III mGluRs (Kamiya et al., 1996). While our results using BoTX make it unlikely that these receptors were targeted by glutamate released from the postsynaptic cell, glutamate could have been generated from other sources (e.g., glia). However, in the presence of the Group II and III mGluR antagonists LY $341495(1 \mu \mathrm{M})$ and MSOP $(200 \mu \mathrm{M})$, respectively, the large difference between control and BAPTA remained (Fig. 5F). These antagonists almost completely reverse the DCG-IV-mediated suppression of MF transmission (Extended Data Fig. 5-1E). It is therefore unlikely that activation of presynaptic mGluR2/3 underlies the suppression of MF-PTP.

\section{Strong presynaptic activity is required for retrograde suppression of glutamate release}

The types of activity under which retrograde suppression of transmitter release manifests could have important implications for the CA3 network. We found that burst-induced facilitation, measured by the ratio of the fifth KAREPSC amplitude to that of the first (P5/P1) in a single burst (five pulses, $25 \mathrm{~Hz}$ ), was not significantly different in control versus BAPTA conditions (Fig. 6A). We also examined the effect of postsynaptic $\mathrm{Ca}^{2+}$ buffering on low-frequency facilitation (LFF), whereby single KAR-EPSCs were evoked, first during $0.1 \mathrm{~Hz}$ basal stimulation, and after switching to $1 \mathrm{~Hz}$. No difference was observed between conditions (Fig. 6B). Thus, for these modest increases in activity, postsynaptic $\mathrm{Ca}^{2+}$ buffering seemed to have no impact on presynaptic transmitter release. Moreover, because frequency facilitation is highly dependent on the starting $\operatorname{Pr}$ (Zucker and Regehr, 2002; Nicoll and Schmitz, 2005; Regehr, 2012), these results argue against a tonic suppression of neurotransmitter release under high postsynaptic $\mathrm{Ca}^{2+}$ buffering conditions.

We next delivered multiple bursts to determine how strong the bursting paradigm must be before retrograde suppression of MF-PTP is observed. To this end, we increased the number of bursts while maintaining both the frequency within a burst $(50 \mathrm{~Hz})$, as well as between bursts $(2 \mathrm{~Hz})$. After three bursts, synaptic responses were similar in both $\mathrm{Ca}^{2+}$ buffering conditions (i.e., control and BAPTA), but a difference emerged after 10 bursts (Fig. $6 C$ ), and a larger difference was also seen after increasing the number of bursts to 50 . In BAPTA-dialyzed cells, there was a difference between 3 and 10 (ANOVA, $F=21.9$; $p<0.05 ; \mathrm{df}=10), 3$ and $25(p<0.001, \mathrm{df}=10), 3$ and 50 $(p<0.001, d f=9), 10$ and $50(p<0.001, d f=11)$, and 25 and 50 bursts $(p<0.05, d f=11)$. Together, these data not only uncover the magnitude of MF-PTP in the absence of a retrograde suppressive signal, but also show that in our BAPTA conditions, a longer bursting paradigm induces stronger MF-PTP. The threshold observed with 10 bursts is relatively modest, highlighting that this form of regulation could likely manifest in vivo.

We next examined whether stronger activation of MFs could overcome the suppressive retrograde signal. To address this possibility, we delivered HFS consisting of three trains of 100 stimuli $(100 \mathrm{~Hz}$ within a train; trains separated by $10 \mathrm{~s}$ ). While a sizeable potentiation was elicited in control cells, the magnitude of MF-PTP was significantly larger in conditions of high $\mathrm{Ca}^{2+}$ buffering (Fig. $6 D$ ). Thus, the putative retrograde signal is strong enough to dampen the PTP evoked even by prolonged high-frequency tetanus.

It has been suggested that the MF-CA3 synapse can operate as a conditional detonator (Treves and Rolls, 1992; Urban et al., 2001; Henze et al., 2002), and a recent study demonstrated that MF-PTP could convert MF-CA3 synapses into full detonators (Vyleta et al., 2016). However, recordings in this study, like many other voltage-clamp studies, were performed under high postsynaptic $\mathrm{Ca}^{2+}$ buffering conditions, i.e., $10 \mathrm{~mm}$ EGTA in the recording pipette. We therefore reassessed the role of 
A

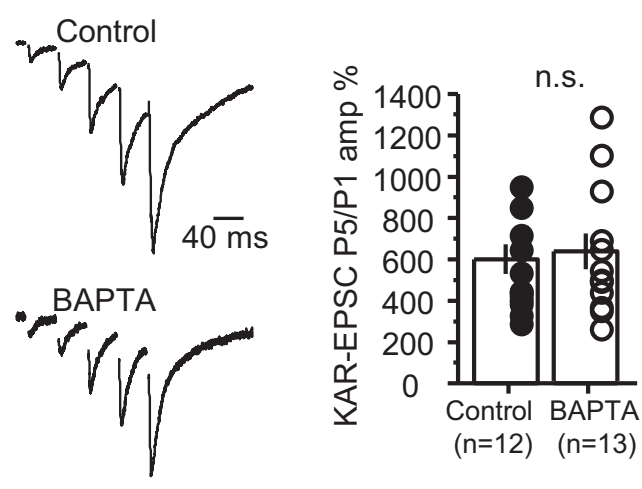

B

B Low frequency facilitation

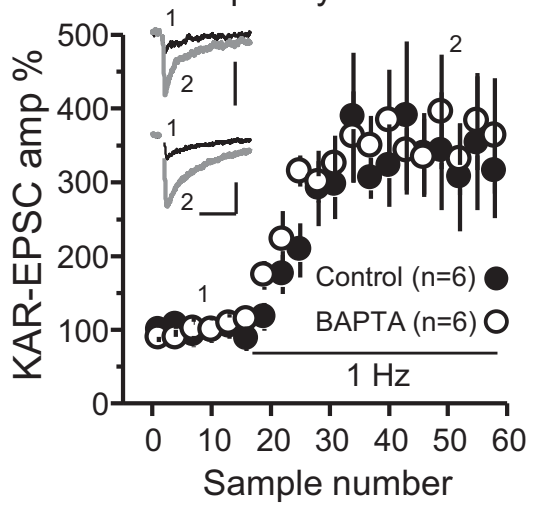

D

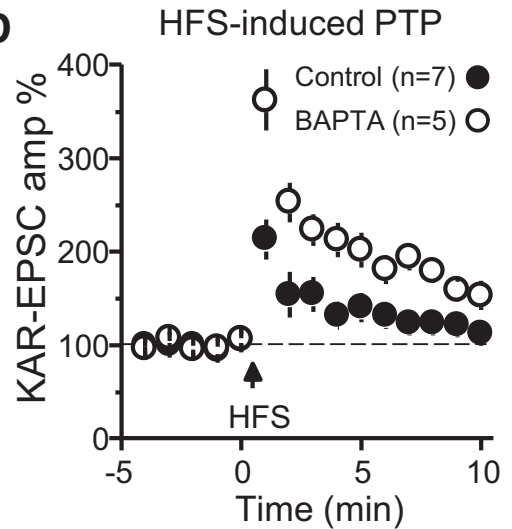

$\mathbf{F}$

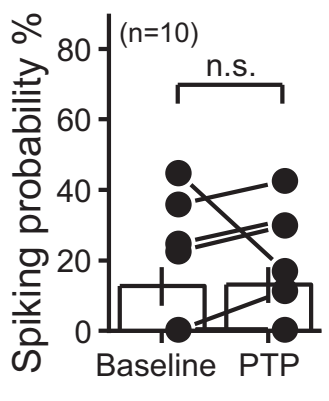

G

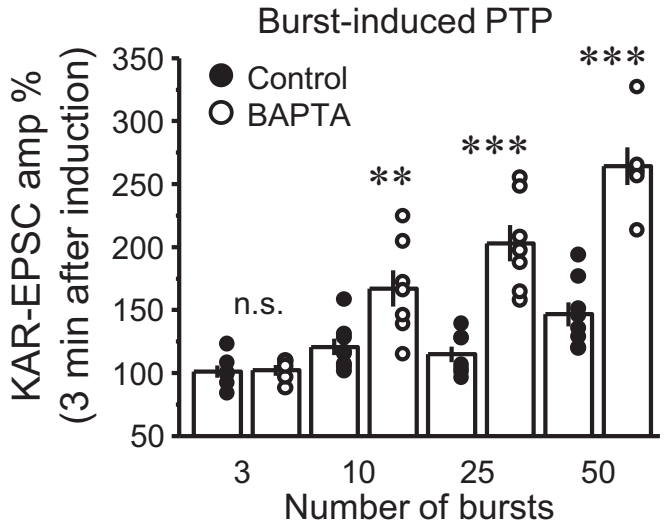

E
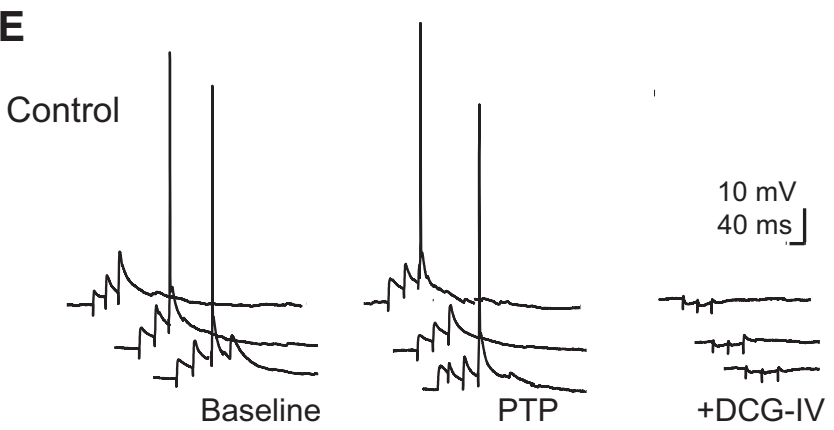

H
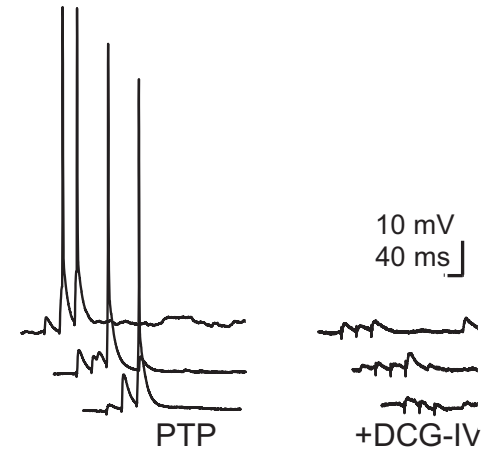

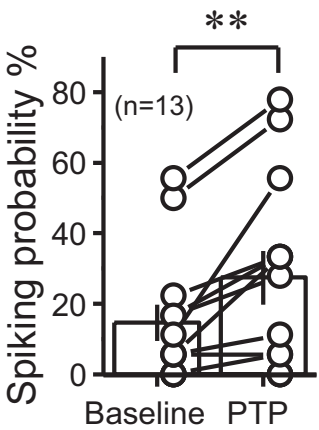

Figure 6. MF-PTP suppression under different patterns of activity. $\boldsymbol{A}$, Five pulses were delivered to MFs for control and BAPTA-dialyzed cells, and the ratio of the fifth KAR-EPSC to the first was taken (P5/P1 control: $6.0 \pm 0.7 ; n=12$; P5/P1 BAPTA: $6.5 \pm 0.9$; $n=13$; control vs BAPTA: $p>0.5$ ). Representative traces (normalized to the amplitude of first EPSC) are shown on the left side. $\boldsymbol{B}$, Summary data showing effect of switching basal stimulation frequency from 0.1 to $1.0 \mathrm{~Hz}$ in control versus BAPTA-dialyzed cells (LFF control: $341 \pm 73 \%$ of baseline; $n=6$; LFF BAPTA: $358 \pm 59 \% ; n=6$; control vs BAPTA: $p>0.5$ ). Insets, Superimposed traces taken at 0.1 and $1.0 \mathrm{~Hz}$. Calibration bars: $40 \mathrm{pA}$ and $40 \mathrm{~ms}$. C, Summary data showing the suppressive effect on MF-PTP induced 
continued

by different number of bursts. Three bursts, control: $101 \pm 5 \%$ of baseline; $n=7$; BAPTA: $102 \pm 4 \%$; $n=5$ (control vs BAPTA: $p>0.5)$. Ten bursts, control: $121 \pm 7 \%$ of baseline; $n=8$; BAPTA: $167 \pm 14 \% ; n=7$ (control vs BAPTA: $p<0.01$ ). Twenty-five bursts: control: $115 \pm 6 \%$ of baseline; $n=7$; BAPTA: $203 \pm 14 \% ; n=7$ (control vs BAPTA: $p<0.001$ ). Fifty bursts: control: $147 \pm 10 \%$ of baseline; $n=8$; BAPTA: $264 \pm 15 \% ; n=6$ (control vs BAPTA: $p<0.001)$. $\boldsymbol{D}$, Effect of HFS (100 pulses at $100 \mathrm{~Hz}, 3 \times$ ) on MF KAREPSCs, with or without BAPTA in the patch pipette (control: $181 \pm 20 \%$ of baseline; $n=7$; BAPTA: $282 \pm 24 \%$; $n=5$; control vs BAPTA: $p<0.01)$. $\boldsymbol{E}-\boldsymbol{H}$, Effects of MF-PTP on CA3 pyramidal neuron firing induced by MF bursting stimulation in current-clamp configuration. No drugs were added to the bath. Control cells loaded with 0.1 mM EGTA (E, $\boldsymbol{F}$ ) showed no significant increase in spike probability after PTP induction (baseline: $12.6 \pm 5.5 \% ; n=10 ;$ PTP: $13.07 \pm 5 \%$; $n=10$; baseline vs PTP: $p>0.5$, Wilcoxon signed-ranked test), whereas in cells loaded with $10 \mathrm{~mm}$ BAPTA $(\boldsymbol{G}, \boldsymbol{H})$ PTP enhanced the probability of firing action potentials (baseline: $14.52 \pm 5.1 \% ; n=10$; PTP: $27 \pm 7.5 \%$; $n=10$; baseline vs PTP: $p<0.01$, Wilcoxon signed-ranked test). n.s., non-significant; ${ }^{* *}, p<0.01 ;{ }^{* * *}, p<0.001$.

PTP in MF detonation using physiological intracellular $\mathrm{Ca}^{2+}$ buffering. To this end, we tested whether PTP induction facilitated the ability of a short MF burst (three stim, $25 \mathrm{~Hz}$ ) to generate action potentials in the postsynaptic CA3 pyramidal neurons loaded with either $0.1 \mathrm{~mm}$ EGTA (control) or 10 mm BAPTA. Consistent with previous findings (Nelson et al., 2003; Roussel et al., 2006), we observed that action potentials were easier to elicit in BAPTA-loaded neurons. A comparable baseline spiking probability between control and BAPTA neurons was achieved by slightly adjusting the stimulus strength and depolarizing the control neurons by $\sim 10 \mathrm{mV}$. We found that the spike probability 3 min post-PTP was significantly enhanced in BAPTA but not control cells (Fig. 6E-H). These results indicate that the contribution of PTP to MF detonation can be overestimated under high postsynaptic $\mathrm{Ca}^{2+}$ buffer recording conditions.

\section{Discussion}

We report here that the $\mathrm{Ca}^{2+}$ buffering capacity of the postsynaptic neuron can significantly impact presynaptically expressed PTP at the hippocampal MF-CA3 synapse. Under normal $\mathrm{Ca}^{2+}$ buffering capacity, as observed during non-invasive recording conditions (e.g., perforated patch recording) that do not significantly alter the physiological intracellular milieu, we found that a bursting induction protocol designed to mimic in vivo activity patterns of GCs triggered a negligible PTP. However, a far greater potentiation was revealed under high postsynaptic $\mathrm{Ca}^{2+}$ buffering conditions. Remarkably, increasing the postsynaptic buffer capacity had no significant effect on the basal Pr, arguing against a tonic suppression of neurotransmitter release. The most parsimonious explanation for our findings is the presence of $\mathrm{a} \mathrm{Ca}^{2+}$-dependent, retrograde signaling mechanism that suppresses PTP. A minimum threshold was required before the phenomenon was observed, above which it operated in a wide range of activity. These results point to a novel, activity-dependent form of negative feedback at the MF-CA3 synapse that may significantly impact DG-CA3 information transfer.

At first glance, our findings contrast starkly with numerous studies that have reported pronounced MF-PTP (for review, see Henze et al., 2000). However, most of these studies elicited MF-PTP with strong repetitive stimulation (e.g., HFS) while monitoring MF transmission with extracellular field recordings. Because of activation of the CA3 network, these experimental conditions not only enable the recruitment of associational-commissural inputs that are commonly interpreted as MF-mediated responses, but also facilitate population spike contamination of (extracellularly recorded) synaptic responses (Henze et al., 2000; Nicoll and Schmitz, 2005). As a result, MF-PTP magnitude can be easily overestimated. Strong MF-PTP was also observed in studies that used more sensitive, single-cell recordings (Zalutsky and Nicoll, 1990; Maccaferri et al., 1998; Vyleta et al., 2016; Vandael et al., 2020), but here again it was typically evoked with a rather non-physiological induction protocol such as HFS. Critically, many such previous studies also loaded postsynaptic neurons with 10 mm EGTA, a standard concentration used in whole-cell studies, both in vitro and in vivo. Indeed, we also observed striking MF-PTP in those conditions (Fig. 2B). Our findings therefore suggest that MF-PTP is tightly controlled when afferent stimulation and postsynaptic $\mathrm{Ca}^{2+}$ buffering are set to more physiological levels.

$A$ rise in postsynaptic $\mathrm{Ca}^{2+}$ is required for most forms of retrograde signaling (Fitzsimonds and Poo, 1998; Regehr et al., 2009). Consistent with this notion, MF-PTP was suppressed when the postsynaptic cell was loaded with high (millimolar) concentrations of EGTA or BAPTA, or with CPA or heparin, all agents that interfere with intracellular $\mathrm{Ca}^{2+}$ rise. To determine the potential source(s) of postsynaptic $\mathrm{Ca}^{2+}$ rise involved in the suppression of MF-PTP, we pharmacologically interfered with these sources one by one. We found that $I P_{3} R-$ mediated $\mathrm{Ca}^{2+}$ release from intracellular stores contributed to the suppression, but that Group I mGluRs and G-protein-coupled signaling alone were insufficient. Importantly, however, we cannot discard synergism of multiple sources leading to the full rise in postsynaptic $\mathrm{Ca}^{2+}$ required for retrograde suppression of MF-PTP, including the contribution of VGCCs in a poorly voltageclamped postsynaptic compartment (Williams and Mitchell, 2008; Beaulieu-Laroche and Harnett, 2018). Interestingly, the endogenous $\mathrm{Ca}^{2+}$ buffering power of CA3 pyramidal neurons is the source of some debate, as some have suggested it is higher than that of CA1 cells (Wang et al., 2004), while others report it is similar (Simons et al., 2009). Further complicating this matter, different endogenous buffers and extrusion mechanisms create short-lived $\mathrm{Ca}^{2+}$ nanodomains which can limit the interaction between $\mathrm{Ca}^{2+}$ and its substrates (Higley and Sabatini, 2008). Our data show little 
PTP when the intracellular composition was not perturbed in perforated patch mode, and robust PTP when the cell was dialyzed with a high concentration of BAPTA (Fig. 2C). This observation would indicate that, regardless of the exact endogenous buffering power of these cells, it is sufficiently low to allow for the postsynaptic neuron to regulate MFPTP.

Retrograde signaling has been proposed to influence PTP, but typically in the opposite direction to our findings. For example, in the Aplysia sensorimotor neuron preparation, injection of BAPTA into the postsynaptic cell depressed PTP (Bao et al., 1997). In the hippocampus, loading CA3 pyramidal neurons with high concentrations of BAPTA (30-50 mm) curtailed PTP and abolished LTP at the MF-CA3 synapse, presumably by blocking the mobilization of a retrograde signal (Yeckel et al., 1999; but see Mellor and Nicoll, 2001). There is also evidence that the receptor tyrosine kinase ephrin $B(E p h B)$ and its membrane-bound ligand ephrin B mediate retrograde communication at MF-CA3 synapses, and that interfering with EphB/ephrin B signaling inhibits both PTP and LTP at MFCA3 synapses (Contractor et al., 2002; Armstrong et al., 2006). Our findings resemble the endocannabinoid-mediated suppression of PTP at the parallel fiber-Purkinje cell synapse via presynaptic type 1 cannabinoid receptors (Beierlein et al., 2007). However, these receptors are not found at MF boutons in the mature brain (Marsicano and Lutz, 1999; Katona et al., 2006; Hofmann et al., 2008; Caiati et al., 2012). While the identity of the putative retrograde signal generated by the postsynaptic neuron remains unidentified, some usual candidates (Regehr et al., 2009) could be discarded. Vesicular, SNARE-dependent exocytosis was ruled out (Fig. $5 \mathrm{C}$ ), indicating that the messenger is likely not a conventional neurotransmitter (e.g., glutamate or GABA). Further evidence against glutamate as a retrograde signaling mediating PTP suppression is the fact that this suppression remains intact after blocking presynaptic Group II and III mGluRs (Fig. 5F). Our findings also argue against the role of another putative signal, nitric oxide (NO) given that its synthesis typically requires the activation of NMDARs (Christopherson et al., 1999; Sattler et al., 1999), which were blocked in most of our experiments. We cannot discard the possibility that PTP suppression involves retrograde signaling via synaptic adhesion molecules. It is worth noting that identifying endocannabinoids as the retrograde messengers mediating the well characterized depolarization-induced suppression of inhibition (DSI) took a decade of work by several groups (Barinaga, 2001). Future studies will have to determine the identity of the presumably non-conventional retrograde signal and the presynaptic substrate responsible for curtailing PTP (Regehr, 2012).

Two recent studies suggested that MF-PTP occurs in vivo (Vandael et al., 2020) and switches MF-CA3 synapses into full detonators (Vyleta et al., 2016). However, our results indicate that the impact of PTP was likely overestimated because recordings in both studies were performed under high, non-physiological $\mathrm{Ca}^{2+}$ buffering conditions (e.g., 10 mm EGTA). PTP has also been reported at MF to inhibitory interneuron synapses (Alle et al., 2001; Mori et al., 2007). Given that MFs make 10 times as many contacts onto inhibitory interneurons as onto CA3 pyramidal cells (Acsády et al., 1998), PTP at MF to interneuron synapses, by presumably activating an inhibitory network, could control the activity of GCs (feed-back inhibition) and detonation of CA3 pyramidal neurons (feed-forward inhibition; Lawrence and McBain, 2003). However, unlike PTP at MF-CA3 synapses, postsynaptic $\mathrm{Ca}^{2+}$ buffering had no impact on PTP magnitude at MF to basket cells synapses in the DG, with similarly robust PTP when the interneuron was loaded with $0.1 \mathrm{~mm}$ EGTA or $10 \mathrm{~mm}$ BAPTA (Alle et al., 2001). Thus, although PTP is observed at distinct MF synapses, the retrograde suppression we report in the present study seems to be unique to the MF-CA3 pyramidal cell synapse.

Relatively strong GC burst activity is needed for engaging suppression of MF-PTP, and the magnitude of this suppression does not seem to be overcome by stronger presynaptic activity (Fig. 6C). Thus, PTP suppression may serve as a powerful mechanism of controlling DGCA3 information transfer following repetitive bursts of GC activity that normally occur during exploratory behaviors (Henze et al., 2002; Pernía-Andrade and Jonas, 2014; Diamantaki et al., 2016; GoodSmith et al., 2017; Senzai and Buzsáki, 2017). Left unchecked, MF-PTP could indirectly lead to runaway activity of the CA3 network and facilitate epileptic activity. Lastly, while the generalizability of PTP suppression remains untested, future studies will be required to determine whether $\mathrm{Ca}^{2+}$ indicators widely used in vitro and in vivo throughout the brain may promote a similar suppression of presynaptic function.

\section{References}

Abbott LF, Regehr WG (2004) Synaptic computation. Nature 431:796-803.

Acsády L, Kamondi A, Sík A, Freund T, Buzsáki G (1998) GABAergic cells are the major postsynaptic targets of mossy fibers in the rat hippocampus. J Neurosci 18:3386-3403.

Alle H, Jonas P, Geiger JR (2001) PTP and LTP at a hippocampal mossy fiber-interneuron synapse. Proc Natl Acad Sci USA 98:14708-14713.

Armstrong JN, Saganich MJ, Xu NJ, Henkemeyer M, Heinemann SF, Contractor A (2006) B-ephrin reverse signaling is required for NMDA-independent long-term potentiation of mossy fibers in the hippocampus. J Neurosci 26:3474-3481.

Bao JX, Kandel ER, Hawkins RD (1997) Involvement of pre- and postsynaptic mechanisms in posttetanic potentiation at Aplysia synapses. Science 275:969-973.

Barinaga M (2001) How cannabinoids work in the brain. Science 291:2530-2531.

Beaulieu-Laroche L, Harnett MT (2018) Dendritic spines prevent synaptic voltage clamp. Neuron 97:75-82.e3.

Beierlein M, Fioravante D, Regehr WG (2007) Differential expression of posttetanic potentiation and retrograde signaling mediate target-dependent short-term synaptic plasticity. Neuron 54:949-959.

Breustedt J, Vogt KE, Miller RJ, Nicoll RA, Schmitz D (2003) Alpha1E-containing $\mathrm{Ca} 2+$ channels are involved in synaptic plasticity. Proc Natl Acad Sci USA 100:12450-12455.

Caiati MD, Sivakumaran S, Lanore F, Mulle C, Richard E, Verrier D, Marsicano G, Miles R, Cherubini E (2012) Developmental regulation of CB1-mediated spike-time dependent depression at immature mossy fiber-CA3 synapses. Sci Rep 2:285. 
Carta M, Lanore F, Rebola N, Szabo Z, Da Silva SV, Lourenço J, Verraes A, Nadler A, Schultz C, Blanchet C, Mulle C (2014) Membrane lipids tune synaptic transmission by direct modulation of presynaptic potassium channels. Neuron 81:787-799.

Castillo PE, Malenka RC, Nicoll RA (1997) Kainate receptors mediate a slow postsynaptic current in hippocampal CA3 neurons. Nature 388:182-186.

Castillo PE, Younts TJ, Chávez AE, Hashimotodani Y (2012) Endocannabinoid signaling and synaptic function. Neuron 76:7081.

Christopherson KS, Hillier BJ, Lim WA, Bredt DS (1999) PSD-95 assembles a ternary complex with the $\mathrm{N}$-methyl-D-aspartic acid receptor and a bivalent neuronal NO synthase PDZ domain. J Biol Chem 274:27467-27473.

Claiborne BJ, Xiang Z, Brown TH (1993) Hippocampal circuitry complicates analysis of long-term potentiation in mossy fiber synapses. Hippocampus 3:115-121.

Contractor A, Rogers C, Maron C, Henkemeyer M, Swanson GT, Heinemann SF (2002) Trans-synaptic Eph receptor-ephrin signaling in hippocampal mossy fiber LTP. Science 296:1864-1869.

Diamantaki M, Frey $M$, Berens $P$, Preston-Ferrer $P$, Burgalossi A (2016) Sparse activity of identified dentate granule cells during spatial exploration. Elife 5:e20252.

Dietrich D, Kirschstein T, Kukley M, Pereverzev A, von der Brelie C, Schneider T, Beck H (2003) Functional specialization of presynaptic Cav2.3 Ca2 + channels. Neuron 39:483-496.

Feinmark SJ, Begum R, Tsvetkov E, Goussakov I, Funk CD, Siegelbaum SA, Bolshakov VY (2003) 12-lipoxygenase metabolites of arachidonic acid mediate metabotropic glutamate receptor-dependent long-term depression at hippocampal CA3-CA1 synapses. J Neurosci 23:11427-11435.

Fitzsimonds RM, Poo MM (1998) Retrograde signaling in the development and modification of synapses. Physiol Rev 78:143-170.

Gerber U, Gee CE, Benquet P (2007) Metabotropic glutamate receptors: intracellular signaling pathways. Curr Opin Pharmacol 7:5661.

GoodSmith D, Chen X, Wang C, Kim SH, Song H, Burgalossi A, Christian KM, Knierim JJ (2017) Spatial representations of granule cells and mossy cells of the dentate gyrus. Neuron 93:677-690.e5.

Griffith WH (1990) Voltage-clamp analysis of posttetanic potentiation of the mossy fiber to CA3 synapse in hippocampus. J Neurophysiol 63:491-501.

Henze DA, Urban NN, Barrionuevo G (2000) The multifarious hippocampal mossy fiber pathway: a review. Neuroscience 98:407-427.

Henze DA, Wittner L, Buzsáki G (2002) Single granule cells reliably discharge targets in the hippocampal CA3 network in vivo. Nat Neurosci 5:790-795.

Higley MJ, Sabatini BL (2008) Calcium signaling in dendrites and spines: practical and functional considerations. Neuron 59:902913.

Hofmann ME, Nahir B, Frazier CJ (2008) Excitatory afferents to CA3 pyramidal cells display differential sensitivity to CB1 dependent inhibition of synaptic transmission. Neuropharmacology 55:11401146.

Jonas P, Major G, Sakmann B (1993) Quantal components of unitary EPSCs at the mossy fibre synapse on CA3 pyramidal cells of rat hippocampus. J Physiol 472:615-663.

Kamiya H, Shinozaki H, Yamamoto C (1996) Activation of metabotropic glutamate receptor type 2/3 suppresses transmission at rat hippocampal mossy fibre synapses. J Physiol 493:447-455.

Kano M, Ohno-Shosaku T, Hashimotodani Y, Uchigashima M, Watanabe M (2009) Endocannabinoid-mediated control of synaptic transmission. Physiol Rev 89:309-380.

Kapur A, Yeckel M, Johnston D (2001) Hippocampal mossy fiber activity evokes $\mathrm{Ca} 2+$ release in CA3 pyramidal neurons via a metabotropic glutamate receptor pathway. Neuroscience 107:59-69.

Katona I, Urbán GM, Wallace M, Ledent C, Jung KM, Piomelli D, Mackie K, Freund TF (2006) Molecular composition of the endocannabinoid system at glutamatergic synapses. J Neurosci 26:5628-5637.
Kukley M, Schwan M, Fredholm BB, Dietrich D (2005) The role of extracellular adenosine in regulating mossy fiber synaptic plasticity. J Neurosci 25:2832-2837.

Kwon HB, Castillo PE (2008a) Role of glutamate autoreceptors at hippocampal mossy fiber synapses. Neuron 60:1082-1094.

Kwon HB, Castillo PE (2008b) Long-term potentiation selectively expressed by NMDA receptors at hippocampal mossy fiber synapses. Neuron 57:108-120.

Lawrence JJ, McBain CJ (2003) Interneuron diversity series: containing the detonation-feedforward inhibition in the CA3 hippocampus. Trends Neurosci 26:631-640.

Lledo PM, Zhang X, Südhof TC, Malenka RC, Nicoll RA (1998) Postsynaptic membrane fusion and long-term potentiation. Science 279:399-403.

Maccaferri G, Tóth K, McBain CJ (1998) Target-specific expression of presynaptic mossy fiber plasticity. Science 279:1368-1370.

Marsicano G, Lutz B (1999) Expression of the cannabinoid receptor $\mathrm{CB} 1$ in distinct neuronal subpopulations in the adult mouse forebrain. Eur J Neurosci 11:4213-4225.

Mellor J, Nicoll RA (2001) Hippocampal mossy fiber LTP is independent of postsynaptic calcium. Nat Neurosci 4:125-126.

Montal M (2010) Botulinum neurotoxin: a marvel of protein design. Annu Rev Biochem 79:591-617.

Moore KA, Nicoll RA, Schmitz D (2003) Adenosine gates synaptic plasticity at hippocampal mossy fiber synapses. Proc Natl Acad Sci USA 100:14397-14402.

Mori M, Gähwiler BH, Gerber U (2007) Recruitment of an inhibitory hippocampal network after bursting in a single granule cell. Proc Natl Acad Sci USA 104:7640-7645.

Nelson AB, Krispel CM, Sekirnjak C, du Lac S (2003) Long-lasting increases in intrinsic excitability triggered by inhibition. Neuron 40:609-620.

Nicoll RA, Schmitz D (2005) Synaptic plasticity at hippocampal mossy fibre synapses. Nat Rev Neurosci 6:863-876.

Pernía-Andrade AJ, Jonas P (2014) Theta-gamma-modulated synaptic currents in hippocampal granule cells in vivo define a mechanism for network oscillations. Neuron 81:140-152.

Regehr WG (2012) Short-term presynaptic plasticity. Cold Spring Harb Perspect Biol 4:a005702.

Regehr WG, Delaney KR, Tank DW (1994) The role of presynaptic calcium in short-term enhancement at the hippocampal mossy fiber synapse. J Neurosci 14:523-537.

Regehr WG, Carey MR, Best AR (2009) Activity-dependent regulation of synapses by retrograde messengers. Neuron 63:154-170.

Reid CA, Fabian-Fine R, Fine A (2001) Postsynaptic calcium transients evoked by activation of individual hippocampal mossy fiber synapses. J Neurosci 21:2206-2214.

Roussel C, Erneux T, Schiffmann SN, Gall D (2006) Modulation of neuronal excitability by intracellular calcium buffering: from spiking to bursting. Cell Calcium 39:455-466.

Salin PA, Scanziani M, Malenka RC, Nicoll RA (1996) Distinct shortterm plasticity at two excitatory synapses in the hippocampus. Proc Natl Acad Sci USA 93:13304-13309.

Sattler R, Xiong Z, Lu WY, Hafner M, MacDonald JF, Tymianski M (1999) Specific coupling of NMDA receptor activation to nitric oxide neurotoxicity by PSD-95 protein. Science 284:1845-1848.

Scanziani M, Salin PA, Vogt KE, Malenka RC, Nicoll RA (1997) Usedependent increases in glutamate concentration activate presynaptic metabotropic glutamate receptors. Nature 385:630-634.

Schiavo G, Matteoli M, Montecucco C (2000) Neurotoxins affecting neuroexocytosis. Physiol Rev 80:717-766.

Senzai Y, Buzsáki G (2017) Physiological properties and behavioral correlates of hippocampal granule cells and mossy cells. Neuron 93:691-704.e5.

Simons SB, Escobedo Y, Yasuda R, Dudek SM (2009) Regional differences in hippocampal calcium handling provide a cellular mechanism for limiting plasticity. Proc Natl Acad Sci USA 106:14080-14084. 
Toth K, Suares G, Lawrence JJ, Philips-Tansey E, McBain CJ (2000) Differential mechanisms of transmission at three types of mossy fiber synapse. J Neurosci 20:8279-8289.

Treves A, Rolls ET (1992) Computational constraints suggest the need for two distinct input systems to the hippocampal CA3 network. Hippocampus 2:189-199.

Urban NN, Henze DA, Barrionuevo G (2001) Revisiting the role of the hippocampal mossy fiber synapse. Hippocampus 11:408-417.

Vandael D, Borges-Merjane C, Zhang X, Jonas P (2020) Short-term plasticity at hippocampal mossy fiber synapses is induced by natural activity patterns and associated with vesicle pool engram formation. Neuron 107:509-521.e7.

Verkhratsky A (2005) Physiology and pathophysiology of the calcium store in the endoplasmic reticulum of neurons. Physiol Rev 85:201-279.

Vyleta NP, Borges-Merjane C, Jonas P (2016) Plasticity-dependent, full detonation at hippocampal mossy fiber-CA3 pyramidal neuron synapses. Elife 5:e17977.
Wang J, Yeckel MF, Johnston D, Zucker RS (2004) Photolysis of postsynaptic caged $\mathrm{Ca} 2+$ can potentiate and depress mossy fiber synaptic responses in rat hippocampal CA3 pyramidal neurons. $J$ Neurophysiol 91:1596-1607.

Weisskopf MG, Nicoll RA (1995) Presynaptic changes during mossy fibre LTP revealed by NMDA receptor-mediated synaptic responses. Nature 376:256-259.

Williams SR, Mitchell SJ (2008) Direct measurement of somatic voltage clamp errors in central neurons. Nat Neurosci 11:790798.

Yeckel MF, Kapur A, Johnston D (1999) Multiple forms of LTP in hippocampal CA3 neurons use a common postsynaptic mechanism. Nat Neurosci 2:625-633.

Zalutsky RA, Nicoll RA (1990) Comparison of two forms of long-term potentiation in single hippocampal neurons. Science 248:16191624.

Zucker RS, Regehr WG (2002) Short-term synaptic plasticity. Annu Rev Physiol 64:355-405. 